\title{
CHAPTER 100
}

TSUNAMI HEIGHT, OAHU, HAWAII: MODEL AND NATURE

by

Jan Malan Jordaan, Jr.*, Assoclate Professor of Civil Eng Ineerıng, Universıty of Delaware, Newark, Delaware

and

William Mansfield Adams, Professor of Geosciences and Director of Tsunam I Research, Hawali Institute of Geophysıcs, Unıversıty of Hawaiı, Honolulu, Hawai I.

\section{Abstract}

A | 20,000 scale model was built of the island of Oahu and neighboring topography. The model was undistorted and rotatable so that an incoming tsunami from any direction could be easily incorporated by turning the $12^{\prime} \times 12^{\prime}$ model to face the wave generator from the desired angle. The wave basın was $30^{\prime}$ wide and $40^{\prime}$ long; with a $1 \cdot 10$ wave absorbing beach situated at the opposite end from the wave generator. The waves were modeled to a vertical scale of $1: 2000$.

The model was supplemented by a small-scale $(1 \cdot 247,500)$ model, also undistorted, in a transparent $6^{\prime} \times 12^{\prime}$ ripple tank. This model represented the eight principal islands of the island chain and their surrounding topography.

Nature data of runup height for four different tsunamis around 0ahu show a strong zocal amplification effect, varying more with respect to fixed positions around the island (prominent features, points, bays, reefs, etc.) rather than with respect to variations in deep sea direction.

A less pronounced local effect was obtained in the model tests and direct point-to-point correlation of model and nature data was not very meaningful beyond a general trend agreement. The orientation effect was similar on the model as in prototype.

* Formerly Associate Professor of CIvil Engineering, University of Hawai I, Honolulu, Hawaı I. 


\section{Introduction}

The general nature of tsunam I waves can best be Illustrated by Fig. I, tIde gage records of tsunamıs at Johnston Island, 700 miles west-southwest of Oahu (Ref. 3). Tsumami records for Oahu show furthermore, considerable variation in the maximum extent of run-up. It was attempted here to obtain in the model records similar to FIg. I for the tsumami run-up around the perimeter of the scale model. Suitable regular wave sequences to approximate the more complicated tsunam I record were arrived at by suecessful trials.

\section{Pilot Tests}

Prel iminary tests were run while the instrumentation was developed and the performance of the model was determıned. The following tests in Table IA were used as a gulde to the later series of tests and served to optimize the wave generation, measurement and control of ambient test conditions in the model. This data is superseded by the tests as in Table 2 which were made under optimum conditıons.

Table IA

Pilot Model Tests

\begin{tabular}{l|c|c|c}
\hline Origin & Direction, $\theta$ & $\begin{array}{c}\text { Large } \\
\text { Model Test } \\
\text { wave perlod }\end{array}$ & $\begin{array}{c}\text { Small } \\
\text { Model Test } \\
\text { wave period } \\
\text { and direction }\end{array}$ \\
\hline Aleutians & $354^{\circ}$ & 1 to $4,5,8$ & - \\
$124^{\circ}$ & $8,10,12 \mathrm{sec}$. & $\begin{array}{c}2 \text { sec. } \\
\left(145^{\circ}, 167 \frac{1}{2}^{\circ}\right. \\
\left.180^{\circ}\right)\end{array}$ \\
\hline
\end{tabular}

\section{Prototype Data}

Information on wave run-up around the shore of Oahu was obtained from the avallable records published by MacDonald, Cox and others (Ref. 1, 2) for the following tsunamis. 


\section{Table I}

Tsunomi Records Examined

\begin{tabular}{ccc}
\hline Date & Origin & Direction, $\theta$ \\
\hline I Aprı 1946 & Aleutians & $354^{\circ}$ \\
5 Nov. 1952 & Kamchatka & $310^{\circ}$ \\
23 May 1960 & Chıle & $124^{\circ}$ \\
27 March 1964 & Alaska & $6^{\circ}$ \\
\hline
\end{tabular}

The prototype data were plotted on polar coordinate graphs centered on the island center, with values at $10^{\circ}$ intervals determined by interpolation for comparison with the model data taken at $10^{\circ}$ intervals around Oahu. The data were replotted after being normalized (divided by the average of the 36 values) for each individual tsunami record. These data showed a similar trend for each tsunamı, in that, independent of the direction of origin, $\theta$, the normalized run-up values showed a consistent increase or decrease relative to the position azımuth angle $B$. Further analysis showed that the principal augmentative effect was associated with certain sections of the coast, hence of fshore topography, rather than the azimuth of the tsunami origin.

\section{Mode Z Data}

The model data were obtained by sensıng the water surface fluctuation at $10^{\circ}$ intervals around the Island by means of immersed floats attached to strain gages. Readings with $2 \%$ accuracy were obtalned for water waves $0.3 \mathrm{~mm}$ in height and $5 \mathrm{~m}$ in wavelength. The amplification factor at the $50 \mathrm{~m}$ (nature) depth contour was determined by dividing the wave height here by that in deep water $(4000 \mathrm{~m})$. The phase lag of wave arrival around the island was also obtained from the record and used as a control on the reliability of the model performance. The phase lag in the model correlated with arrival times of waves around the $\mathrm{s}$ sland obtaıned from wave refraction diagrams (MacDonald, Shepard, Cox, and Cox and Mink).

\section{Modez-Prototype Correzation} 2946 and 2952 Tsunomis

These tsunamis arrived on Qahu from the north to northwest and were not materially influenced by the neighboring islands. The model tests showed firstly a rather marginal correlation with the prototype values, about a 0.4 correlation. When normal ized, the model tests for 
three wave periods ( $8,10,12$ seconds model) showed a consistent agreement with the hypothesis above that the principal augmentative effect is due to the submarine topography and hence varies with the location angle $\beta$ more strongly than with the wave original direction angle $\theta$. Examınation of the areas of poor and even negative correlation between the model and prototype showed that these were where low values in nature were associated with medium-high values in the model. The apparent reason was the presence of coral barrier reefs in nature, which were too near the coastl ine or too shallow to be minutely scalable in the model.

\section{Tsunam}

The Chilean tsunami was simulated lastly on the model because of the inherent complication caused by the presence of four islands in I Ine with the origin of the wave. In an effort to determine the incident wave directions to be used near Oahu for the simulation, a series of tests was made on the small scale model of all the islands, Table 2. Its wave generator was set up in three separate test runs to generate waves from the south, southeast and SSE directions in turn. Wave heights were recorded near the Oahu island perimeter at 12 locations, using the same gages as used on the large model. The normalized data was plotted on a polar graph, and found to agree with the azımuthal distribution of the 1946,1952 tsunamis on the large model. The local wave crest orientation, however, was not readily determinable.

A wave refraction diagram was thereupon prepared to determine local wave direction input using the avaılable transpacif ic wave refraction diagram presented by MacDonald et al (Ref. I) for obtainIng the incident direction of $135^{\circ}$ southeast of Hawail island. The local wave refraction and diffraction by the wave front method was carried out by $A$. Fallon and the wave crests and orthogonals determined. It was found that the incident wave near Oahu is an interrupted tsunam I wave-front, refracted to an average approach direction of $124^{\circ}$, with the two branches diffracting on each side around the four islands Hawa II, Mauı, Lanai, and Molokaı, in turn, to approach Oahu from two angles of $80^{\circ}$ and $190^{\circ}$, reach Ing the shores on elther side almost simultaneously.

The wave was simulated by al igning the model island's north at $-124^{\circ}$ to the line normal towards the wave generator, and interrupting a length of $10 \mathrm{ft}$. In front of the central portion of the wave generator by an impervious wave absorbing barrier (FIg. 3). This resulted in two diffracted as well as refracted wave systems sweeping in from the end portions of the wave generator and approximately representing the desired condition in nature. 
The model tests were completed in July 1968 with the running of a series of tests with the above simulated tsunami origin from the south-east to determine the shoreline wave distribution for the 1960 Chılean tsunamı event.

The data for three parallel cases were then rigorously analyzed, namely, the following three cases:

Table 2

Final Model Test Data Series

\begin{tabular}{cccc} 
Series & $\begin{array}{l}\text { Direction } \\
\text { from North, } \theta\end{array}$ & $\begin{array}{l}\text { Source and data of } \\
\text { simulated tsunami }\end{array}$ & $\begin{array}{c}\text { Wave periods } \\
\text { In model }\end{array}$ \\
\hline B & $354^{\circ}$ & Aleutians, 1946 & $8,10,12 \mathrm{sec}$. \\
C & $310^{\circ}$ & Kamchatka, 1952 & $8,10,12 \mathrm{sec}$. \\
\hline
\end{tabular}

\section{Description of Test Procedure}

For each test case, $A, B$, or $C$, there were altogether 36 wave measuring points, spaced $10^{\circ}$ apart around the 50 meter (nature) deep perimeter of the Island. At each point, as well as at a deep water location, wave probes were placed and records obtained for each of a series of four waves of $8,10,12$ seconds, respectively. The wave generator was oriented relative to the model to generate a wave from the required direction. To accomplish this orientation, the model was rotated on its turntable and the offshore slopes adjusted to conform approximately to the underwater ridge connecting the islands. The wave period was then set, for 8,10 , and 12 seconds in turn and the generator run for four cycles in each case, creating four wave crests and starting with a crest. The record obtained contalned the time-trace of the wave in deep water near the wave generator, and at the successive shorel ine positions with $10^{\circ}$ increments where the other gage was located. Since the two gages were nominally identical and were calibrated to prove this identical I Inear response, the shorel ine amplification of the wave was obtainable directly by reading the trough to crest values from the two traces and dividing the shallow water value by the deep water or 


\begin{abstract}
"reference value". This was done for two selected waves out of the sequence of four successive crests; namely (a) the first crest, measured from undisturbed level, (b) the third crest measured from the preceding trough level. These were called (a) "First arrival", (b) "third wave", respectively.
\end{abstract}

\title{
Analysis of Data
}

With three wave origin direction conditions and three periods at each direction, there were thus nine distributions of wave amplification of the "first arrival" and the "third wave" around the Island. In order to abstract any existent general trend, first the distributions for $8,10,12$ seconds were added together for each direction, giving a set of three distributions (for the three directions: A, B, C) for "first arrival" amplification around the island, and a corresponding set of three distributions for the "third wave" amplification around the island.

\section{Trends of Model Data Analyzed}

Upon inspection of these six distributions it was found that two clear trends emerged.

1. The "first arrival" amplification showed a strong correlation with original wave approach direction, the amplification being a maximum approximately at the azimuth position around the island which faces the incomıng wave system, and decl Inıng towards minimum at points $\pm 120^{\circ}$ away from that maximum position (with a smaller secondary maximum at the position diametrically opposite).

2. The "third wave" amplificatıon, showed a strong correlation with individual features around the island periphery such as bays and points of land. The correlation with features appeared to be ascribable to resonant conditions being excited in some of the larger bays and bights and around headlands. This resonance was reached by the time of "third wave", but not the first, and persisted as a gradually dimınıshıng surge after the sequence of four waves from the generator was over.

\section{Data Presentation}

The trends for $8,10,12$ second perlod (model times)* 
waves were constant with each other and, although there were minor variations, the amplification distribution patterns were sufficientiy similar that it is concluded that there were no sudden trend reversals likely with a slight period increase or decrease, and that an average of the data for the three periods was a well-enough representation of a typical tsunamı case.

The final data presentation is therefore in the following form.

1. Distribution of "first arrival" amplification with respect to angle between shoreline position and original wave direction for each of three cases (Fig. 4).

2. Distribution of (I) above for the three cases combıned (FIg. 5).

3. Distribution of "third wave" amplification with respect to angle of shoreline position with true north for each of three cases of tsunamı origin (FIg. 6).

4. Distribution of (3) above for the three cases combined (FIg. 7).

This model data is then comparable to prototype tsunami data from run-up records published (Refs. 1, 2).

\section{Prototype Data}

Data for the three cases, A, B, C, (Table 2) were obtained from published tables and were plotted and digitized by $10^{\circ}$ intervals around the island periphery to facilitate model to prototype correlations ( $F$ Ig. 8, typ). Since there was no information on the "deep water wave height" in the prototype, and since the three cases $A, B$, $\mathrm{C}$ in the prototype had most I Ikely different deep water wave heights, it was decided to remove a possible bias when comparing these to model data where $A, B, C$ all had the same deep water wave height as follows

The thirty-six digitized values of shorel ine run-up height in nature for each case ( $A, B$, or $C$ ) were added and an average value obtained. The individual values were then divided by this average. It was assumed this average would be proportional to the non- avallable "deep water wave value", (FIg. 9).

\section{Prototype Trends}

The data when so processed revealed a trend which agreed for all three cases, namely, a correlation of high values of relative shoreline run-up amplification with position around the island. For instance, the shorel ine run-up would be high at a certain location compared to the average around the island, regardless of whether the tsunami originated from north, northwest or southeast. A fourth case, 1957 tsunaml, was also compared with this trend and found to agree as well. 


\section{Model/Prototype Correlations}

Comparison of an individual model test with the prototype run-up distribution generally was not very encouraging (FIg. 10). It would agree in certain respects but not in others. Another test at a different period would give confl Icting trends (FIg. II). It was realized that to attempt correlations by eye would be likely to introduce personal bias, as to whether the model/prototype correlation was good, bad, or indifferent.

A rigorous correlation study was made for selected model test distributions for the 4 sec. period and Aleutian 1946 tsunami condition which formed part of the prliminary series of verification tests. The correlation study revealed fairly weak correlations at first, and after a major improvement in the offshore topography in the island model was made, the correlation was improved to 0.4 ( 1.0 being Ideal, and 0 being no correlation).

It was concluded that two factors contributed to an apparent lack of strong model to prototype data correlation.

1. Selectivity of model test conditions, which do not cover all possibilities of wave period and resonant interaction that might all contribute to the highest water mark in nature.

2. Scale-effect, which influences the ultimate behavior of the water's edge. In nature the wave might break and reach pretentious heights against cliffs, in the model the topography is considerably generalized and surface tension prevents breaking of the very modest wave oscillations. Furthermore, the model data is taken for practical purposes at some distance from the actual shoreline ( -50 meter contour about 3 to 6 inches out from the water's edge in the model) whereas the nature data is taken from the debris l ine left by the actual water I ine excursion inland.

Fo avoid arriving at spurious correlations in some instances and nore at others, the only comparison of model and prototype finally presented consists of comparing with each other (1) the distribution of "thild-wave heights" around the model, (which showed a strong correspondence with position around perimeter) and (II) the distribution of "maximum relative run-up" around the prototype island in nature (which likewise showed a strong correspondence with position around the perimeter). Comparing (1) with (1I), the result is not a perfect match, and in fact is a rather poor agreement, although somewhat better in certain places than in others (Fig. 12). 
Causes for Lack of Positive Model/Prototype Agreement are.

I. The effects of nearshore submerged features, coral reefs, basalt outcrops, are not reproduced in the model due to the large scalereduction of $1.20,000$. This is best seen in Kaneohe Bay and Kaena Point. The model data for each of these locations gives essentially one value respectively. MacDonald, Shepard and Cox in the Ir paper on the 1946 Aleut Ian tsunam I (Ref. I) show how the tsunam I run-up varied near Kaena Point, and ascribe this due to coral reef outcrops. In the model the reefs are not reproducible and the water depth is of the same magn 1 tude as the wave height. At Kaneohe Bay the reported surge is about $4 \mathrm{ft}$. maximum. The use of a $10 \times$ greater scale for wave height in the model is perhaps the cause of questionable behavior in very shallow areas I I ke Kaneohe Bay, where reef outcrops could not be represented on model scale.

2. The effect of the model basin boundaries, and partial reflection and return of wave energy from the wave absorber beach in the basın.

In nature the interaction of a "monochromatı" train of waves and an Island of arbitrary shape leads to a scattering in radiating fashion of all the wave reflection that takes place off the island perimeter. Apart from some multiple reflections between adjacent shorelines, this reflected energy radıates outwards eventually to be lost from the system. In the model, however, it is practically impossible to avoid some return of scattered energy from the confinıng side walls of the basın. The waves passing the model are intended to be perfectly absorbed by a sloping beach covered with rubberized hair Tests showed that about $60 \%$ of the wave amplitude is absorbed and $40 \%$ returns to form a partial standing wave system with the incoming waves. The reflected waves eventually reflect once more off the wave generator end and decay eventually as standing waves having several nodal systems. 
General Discussion on Use of a Sequence of Waves

For the reason above of partial reflection by the basin boundaries, testing with a continuous train of waves would not be valid as some of the basın nodal l ines would intersect the Island perimeter and give spurious values of zero amplification, whereas the basin antinodal I Ines would give exaggerated amplification values.

The use of a short sequence of several waves (In this case 4) does permit data to be obtained before the reflected waves return from the beach and sidewall to interact with the amplification of the traveling wave system. The purest information will be obtained with a single crest or trough, since the return signal will be identifiable as a separate single wave of smaller amplitude occurring later in the record. Use of a single or solitary wave would give essentially the same data as the leadIng wave of a short sequence, but since the solitary waves does not have a definite period, no information on resonance behavior of adjacent shorelines would be obtalned. The use of a sequence of four waves was then decided upon by observation of the optimum behavior of traces obtained with 1,2, 3, 4, and more wave sequences (FIg. 13).

\section{Evaluation of Reliability of Model Data}

The model results are quantitative but are not to be interpreted as quantitative predictions of prototype behavior; because:

1. Prototype wave height input is unknown, hence model wave height input is an arbitrary choice.

2. Prototype waves are spectral, whereas model waves are monochromatı. Absolute predictability comes nearest in the first crest, and here the model results agree markedly well with theoretical prediction for an idealızed conical island.

3. The ultimate run-up in the prototype is greatly dependent on non-modelable features, e.g., cliffs, reefs, perimeter roads and roadside features, canefields, tropical vegetation, houses and streets, buildings, yards and lands.

Apart from the above I Imitations the model data are subject to certain artificially-imposed restrictions:

1. Subjectivity in selection of wave period and origin, especially in a complicated case like the 1960 Chile tsunami which is prior-refracted by four other islands. 
2. Reflection and partial standing waves caused by side and end walls and beach in model basin.

3. The model data are more reliable for the first arrival than for the later waves.

4. The model data are considered more reliable on the exposed shore than on the lee shore with reference to the wave origin because the lee shore receives in addition to the refracted incoming wave, also the unrealistic partial reflection from the absorbing beach.

5. The data from the model for the Barber's PolntPearl Harbor-Diamond Head-Koko Head area appear to give higher wave amplification than experienced in nature for two of the three test cases this is the lee-side with respect to incoming waves, and therefore subject to a back reflection from the model basin beach. For the third case (ChIle 1960) the pre-conditioning of the incoming wave, to strike the south and east shores in a fashion in accordance with the theoretical wave refraction pattern (produced by the ridge to the south east forming the four islands south of Oahu) was not fully achieved. There is, therefore, some uncertainty in the data for this 1960 Chile wave condition which is more so on the exposed south shores.

6. The data obtaıned served to Illustrate partially the type of general behavior that the tsunam I wave system undergoes in its interaction with the nearshore island topography.

Conclusions

The model study of tsunam I wave amp I If Ication around Oahu yielded quantitative data which correlate to a certain extent with field data. It yielded qualitative understanding of the phenomena involved in the process of interpreting the results obtained and increasing the precision of measurement and control of test procedure.

Although the model data in itself do not show sufficiently strong correlations with observed data to permit detall prediction of Inundation levels given a certain wave height, period and orientation, nevertheless a qualitative generalized behavior pattern is 
evident, as has been stated in Trends of Model Data Analyzed. The prototype data trends also found in the course of this study are remarkably consistent. It is hoped that tsunami forecasting could make use of these two trends in arriving at a decision to call a tsunamı alert, or to determıne the area to be evacuated.

\section{References}

1. MacDonald, G., Shepard, F.P., and Cox, D.C., The Tsunami of April 1946 in the Hawal Ian Islands; Pacıfic Science, January 1947. Scripps Institute of Oceanography, Bul1. 5, 6, 1960, pp. 391-528.

2. Cox, D.C. and Mink, J.F., The Tsunamı of 23 May 1960, in the Hawalian Islands, Bull. Selsm. Soc. of Am., Vol. 53, No. 6, pp. 1101-1209, December 1963.

3. Wennekens, P.M., Office of Naval Research report, "Tsunamı vs. Johnston. Island", and HawalI Institute of Geophysics Records.

4. Havelock, T.H., "The Pressure of Water Waves Upon a Fixed Obstacle", Proc. Roy. Soc. (Lond.), Vol. 175A, 18 July 1940, pp. 409-415.

\section{Acknowledgments}

This research was sponsored by the National Science Foundation under Grant No. GK 1374, and was performed at the Look Laboratory of Oceanographic Engineerıng, Unıversity of Hawal I. The principal research assistance was provided by Mr T.D. Krishna Kartha and Mr A.R. Fallon, Research Associates. The assistance of Mr. G. Pararas-Carayannis and of the secretarial staff of the Tsunam I Group, Hawal I Institute of Geophysics, and of the Civil Engineering Department staff, University of Delaware is gratefully acknowledged. 


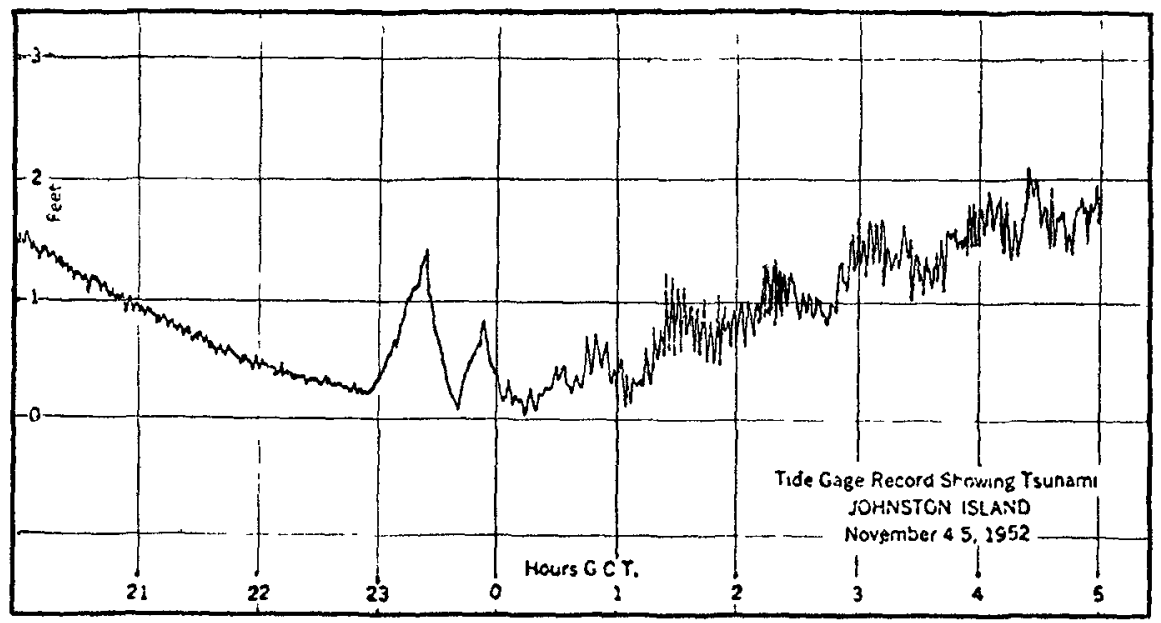

KAMTCHATKA

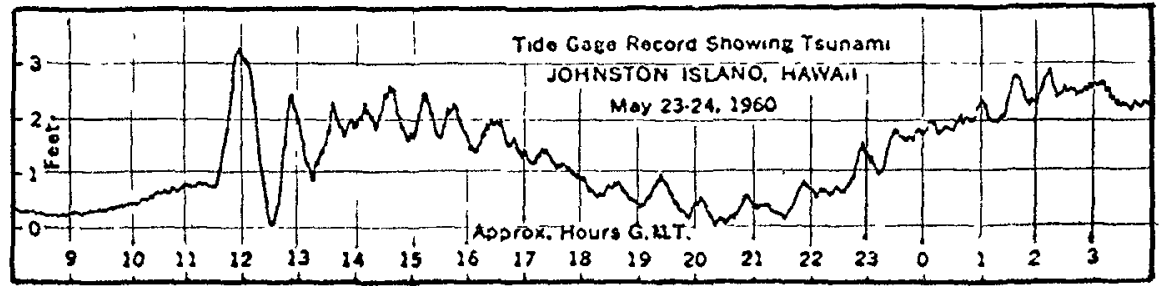

CHILE

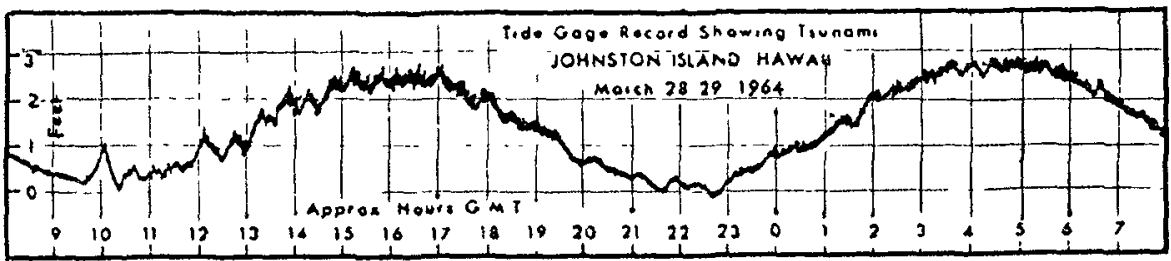

After P.M. Wennekens, Ref. 3.

ALASKA

Figure 1. Tide Gage Records Showing Tsunamis at Johnston Island, Pacific Ocean Lat. N. $16^{\circ} 45^{\prime}$, Long. W. $169^{\circ} 31^{\prime}$. 


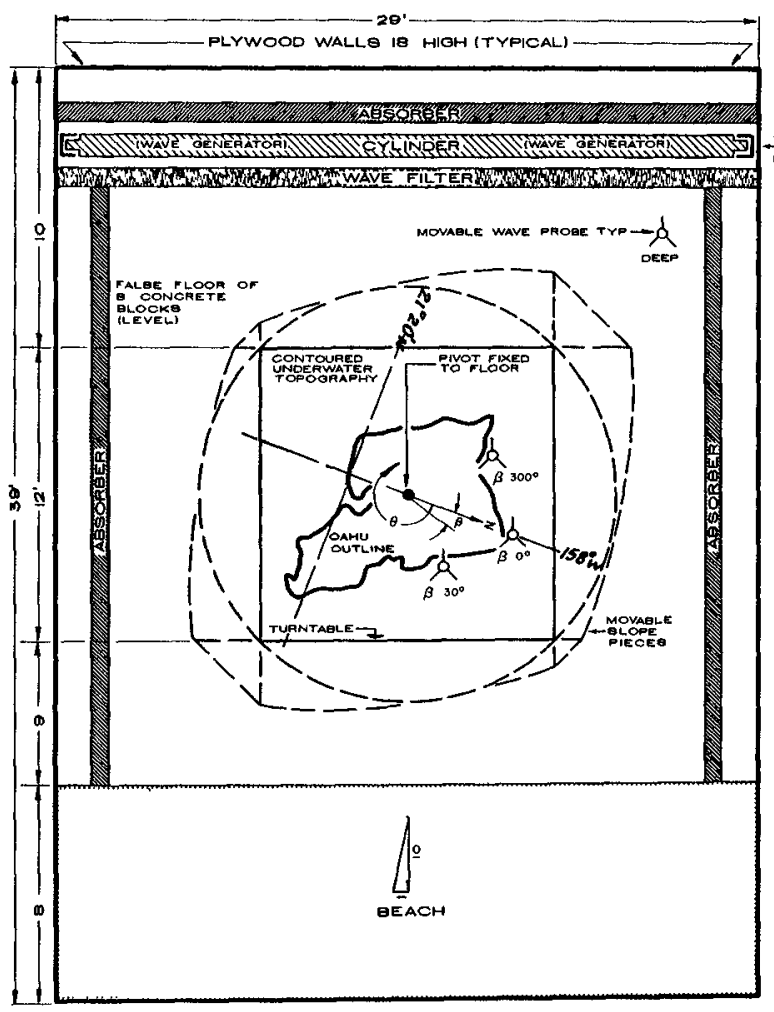

FIGURE 2 OAHU TSUNAMI RUN-UP MODEL.

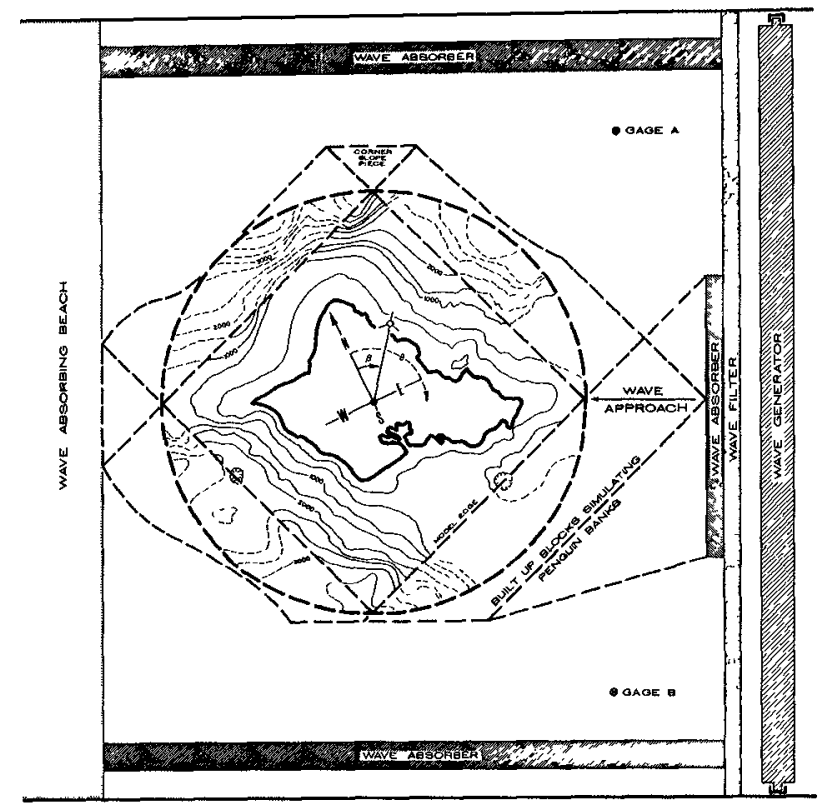

FIGURE 3 TSUNAMI RUNUP MODEL, OAHU SHOWN FOR 1960 CHILE 


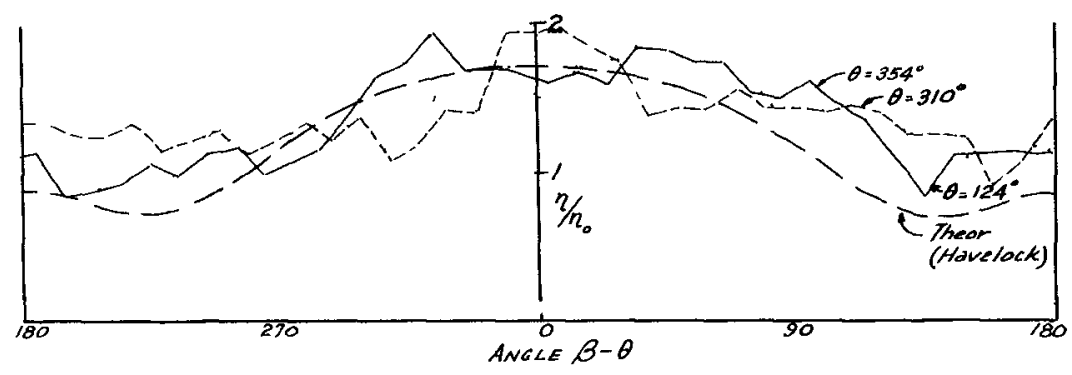

Figure 4. Model data, Initial crest amplification.

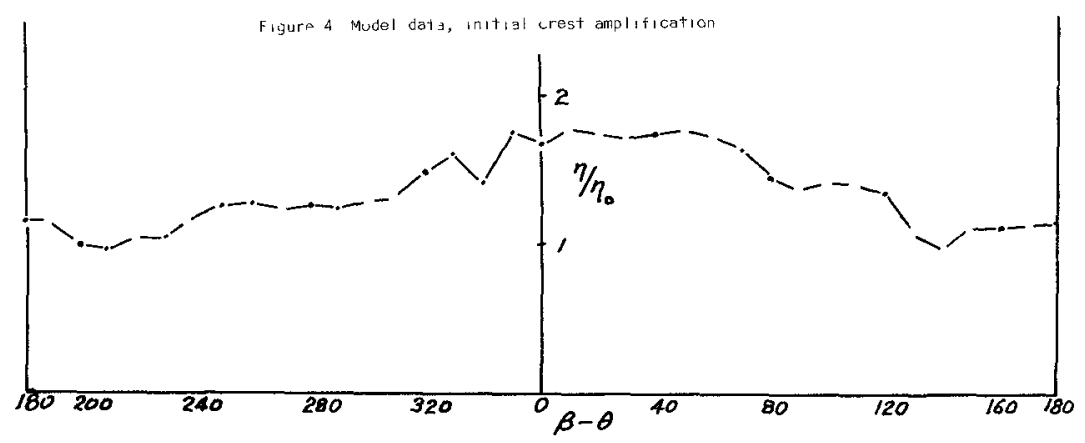

Figure 5. Average of three cases, initial crest amplification.
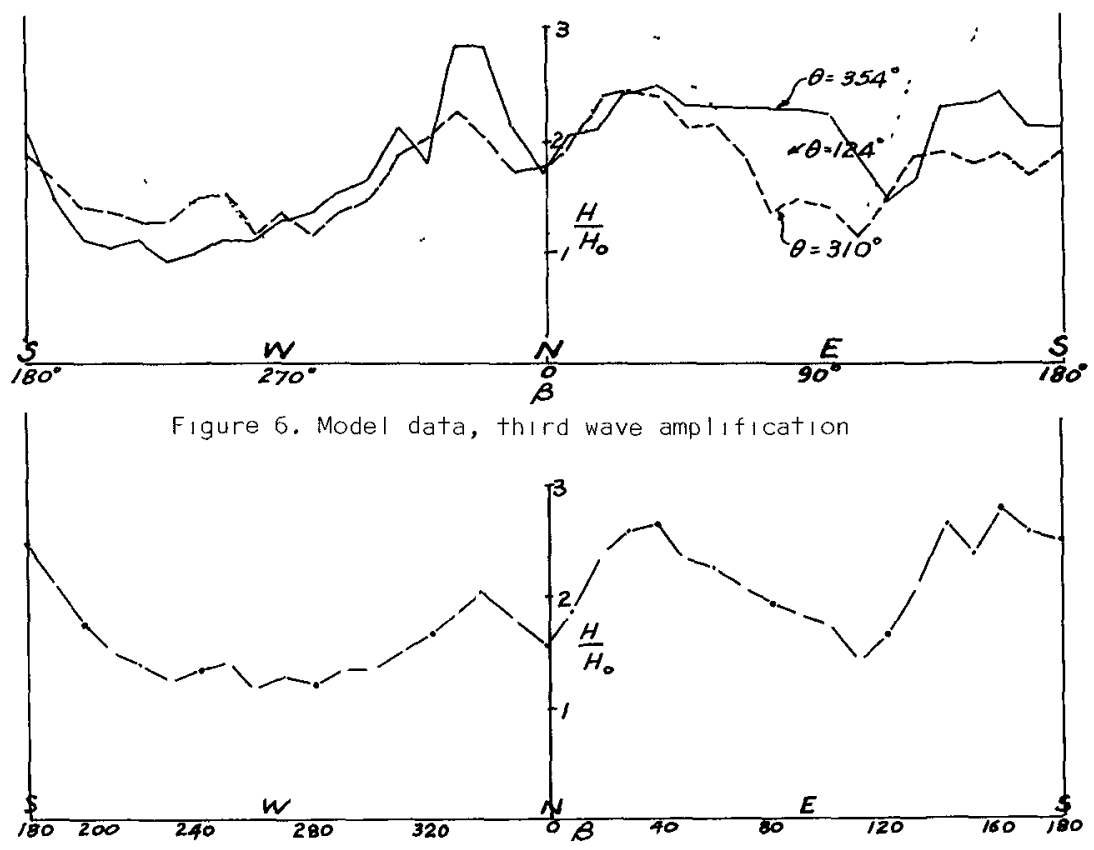

Figure 7. Average of three cases, third wave amplification. 


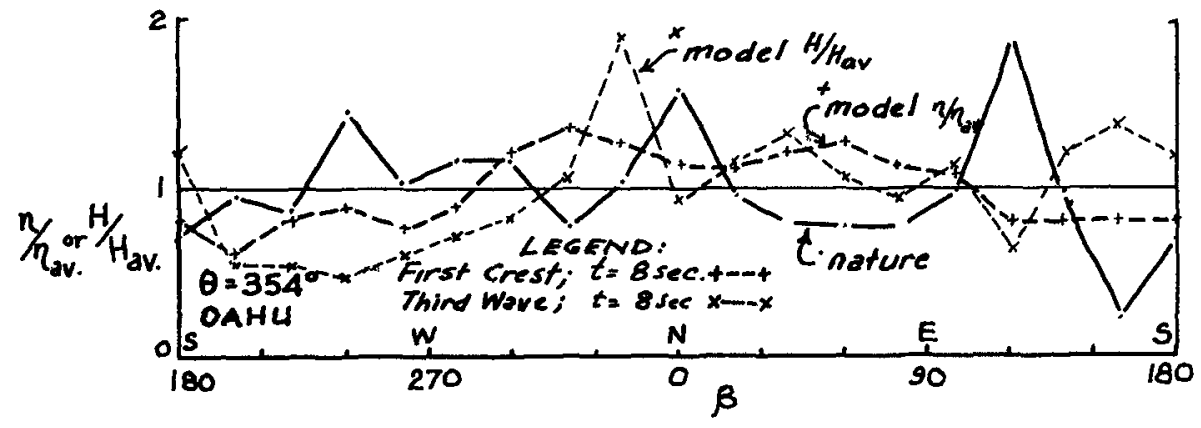

Figure 8. Typıcal model-prototype correlation of data.

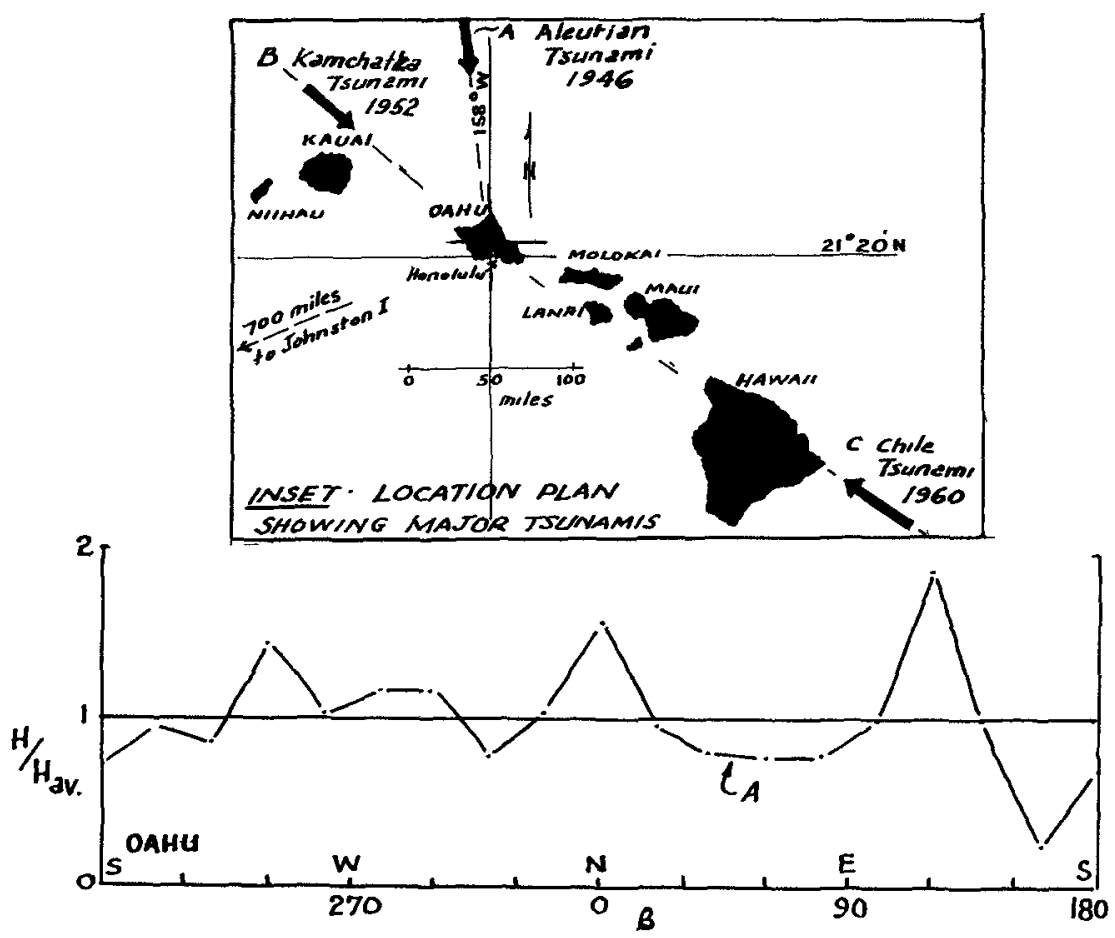

Figure 9. Average of prototype distribution of tsunam relative heights for three tsunamis. 


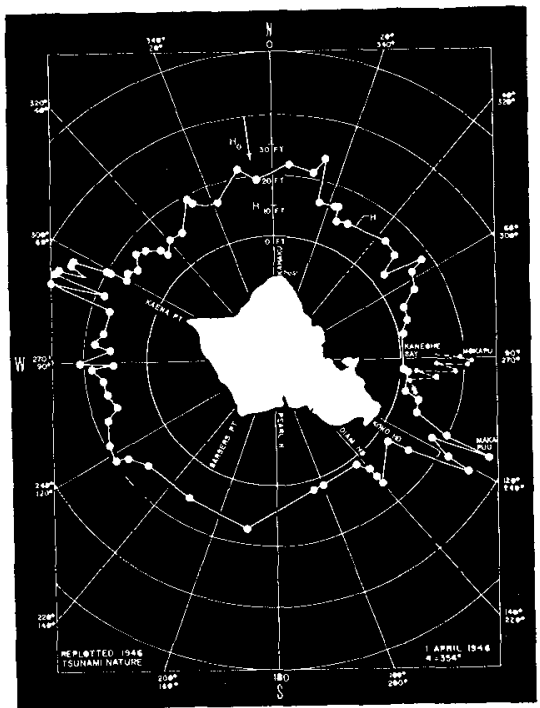

(a)

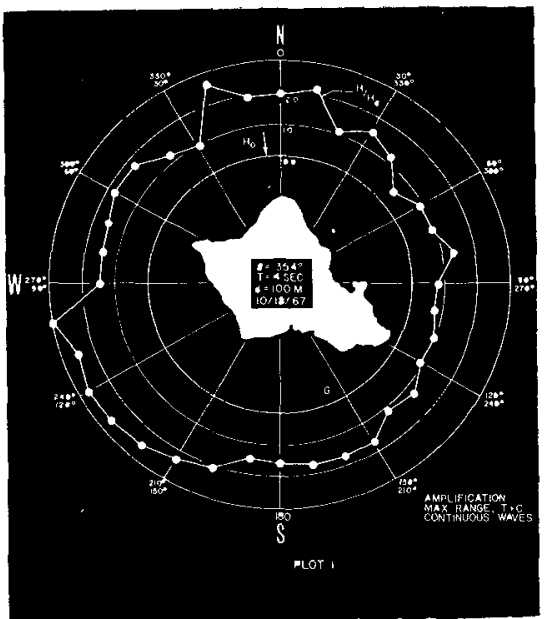

(b)

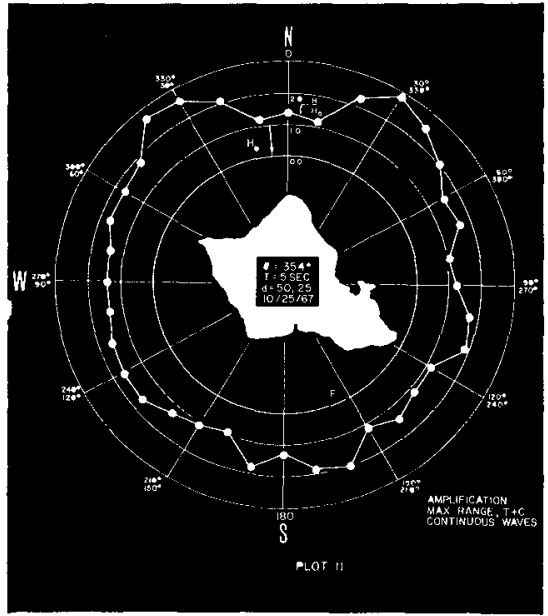

(C)

Figure 10. Prototype and Model Data for two periods, $\theta=354^{\circ}$, Aleut Ian Tsunamı.

(a) Prototype (nature)

(b) Model 4 - second period, continuous waves

(c) Model 5 - second period, continuous waves 

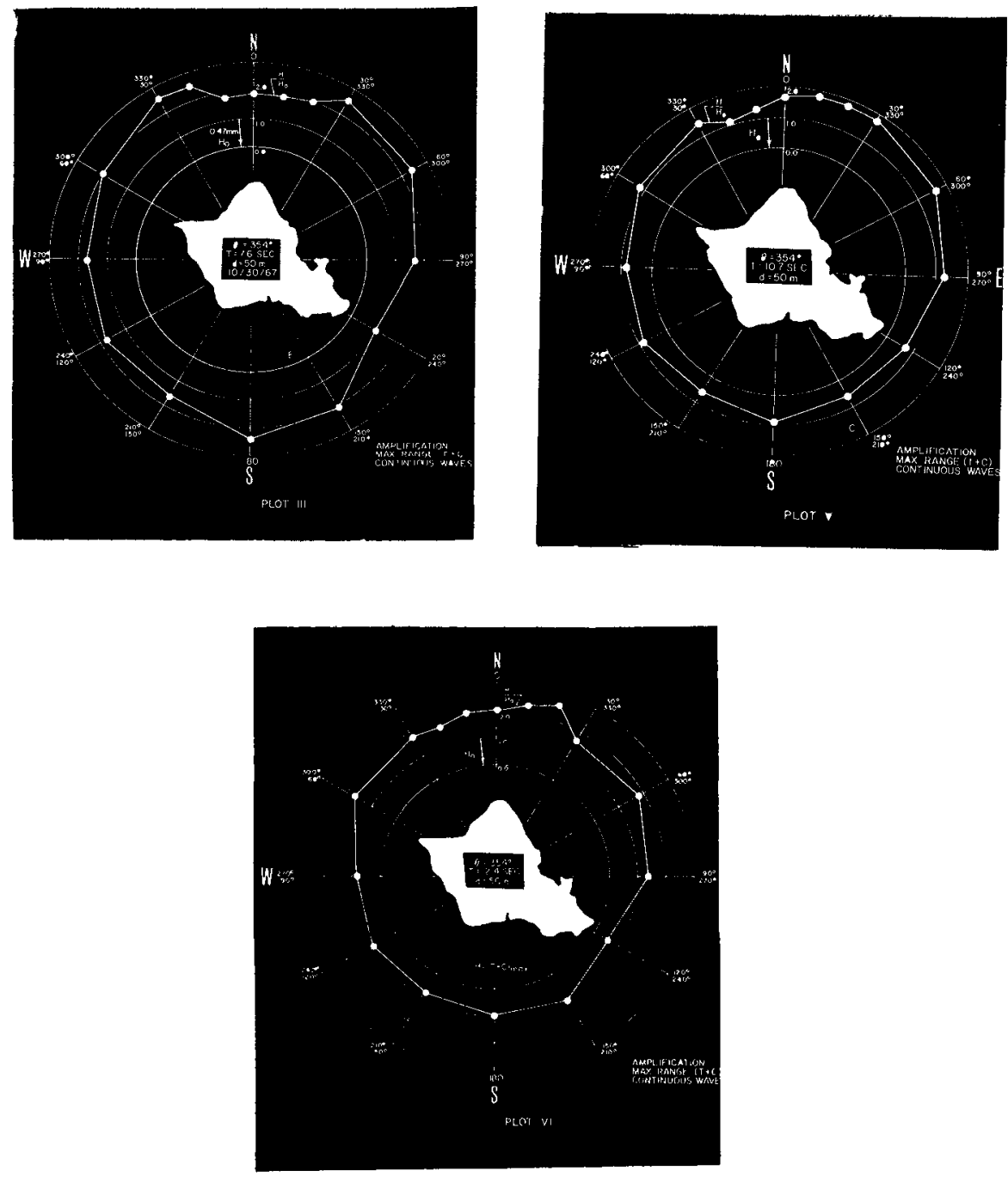

Figure II. Model data, showing effect of further variation of perlod, $7.6 \mathrm{sec} ., 10.7 \mathrm{sec}$, and $12.4 \mathrm{sec}$, respectively. 


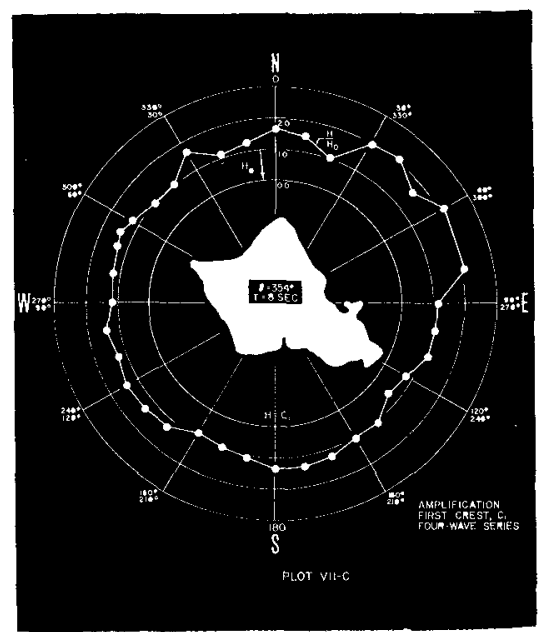

(a)

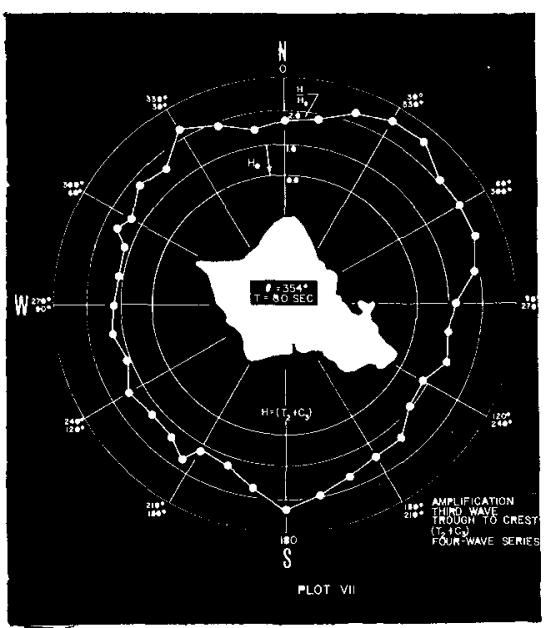

(C)

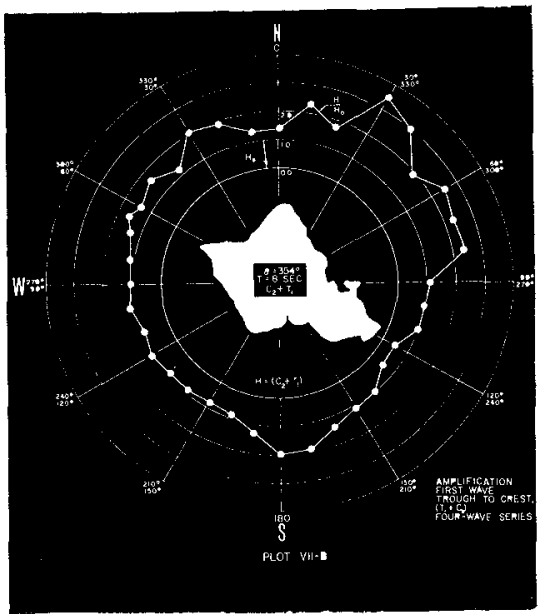

(b)

Figure 12. Comparison of distribution of (a) amplitude of initial crest, (b) height of wave first trough to second crest, (c) helght of third wave (second trough to third crest), for an $8 \mathrm{sec}$. period, four wave sequence, as in Fig. 13. 


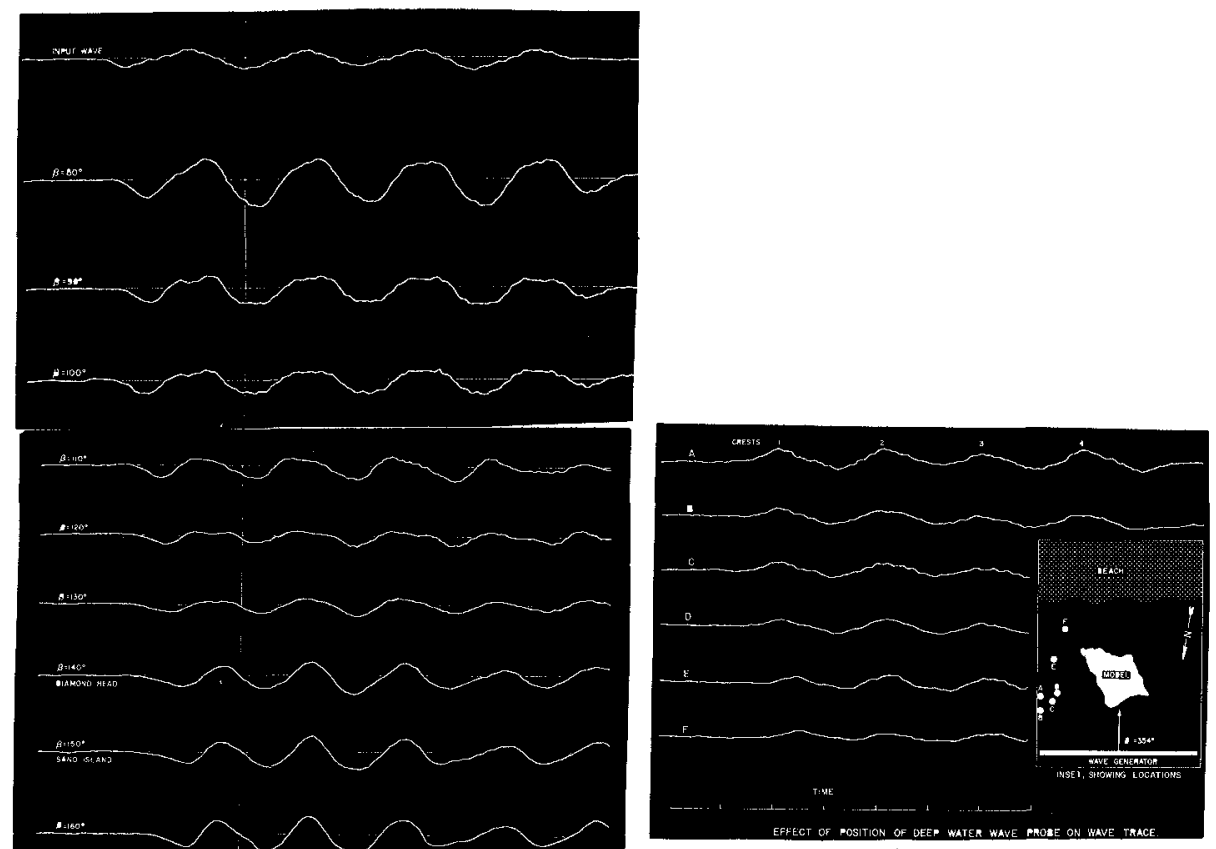

(b)

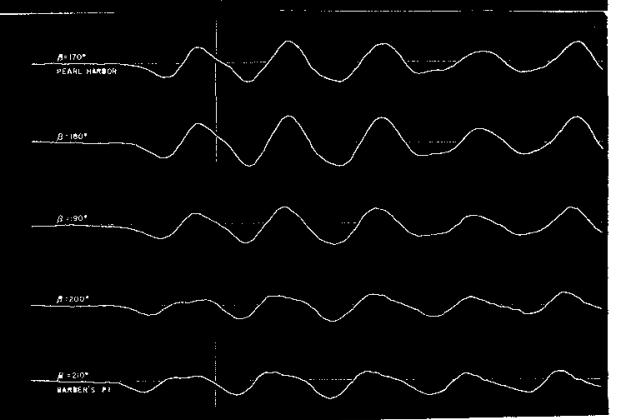

(a)

Figure 13. (a) Typical data sequence, 8 sec. period, four waves (traces shown inverted). Plot of data in Fig. 12-c (Plot VII-B).

(b) Comparison of same wave sequence at six different positions in Test Basın (traces shown right way up). 